\title{
Characterization and kinetic study of Diels-Alder reaction: Detailed study on $N$-phenylmaleimide and furan based benzoxazine with potential self-healing application
}

\author{
Ž. Štirn, A. Ručigaj, M. Krajnc* \\ University of Ljubljana, Faculty of Chemistry and Chemical Technology, Večna pot 113, 1000 Ljubljana, Slovenia
}

Received 30 November 2015; accepted in revised form 31 January 2016

\begin{abstract}
The Diels-Alder reaction between $N$-phenylmaleimide and benzoxazine bearing furan group was investigated for the purpose of successful appliance of self-healing in benzoxazine polymer networks. The reaction as a function of temperature/time was performed in molten state and in a solution, where also the kinetic study was performed. The Diels-Alder reaction leads to a mixture of two diastereomers: endo presented at lower cyclo-reversion temperature and exo at higher. Therefore, the conversion rates and exo/endo ratio were studied in detail for both systems. For instance, in molten state the Diels-Alder reaction was triggered by the temperature of the melting point at $60^{\circ} \mathrm{C}$ with exo/endo ratio preferable to the endo adduct. The study of the kinetics in a solution revealed that the Diels-Alder reaction followed typical bimolecular reversible second-order reaction. The activation energies were close to the previous literature data; 48.4 and $51.9 \mathrm{~kJ} \cdot \mathrm{mol}^{-1}$ for Diels-Alder reaction, and 91.0 and $102.3 \mathrm{~kJ} \cdot \mathrm{mol}^{-1}$ for retro-Diels-Alder reaction, in acetonitrile and chloroform, respectively. The reaction equilibrium in a solution is much more affected by the retro-Diels-Alder reaction than in a molten state. This study shows detailed investigation of DA reaction and provides beneficial knowledge for further use in self-healing polymer networks.
\end{abstract}

Keywords: thermal properties, Diels-Alder reaction, kinetics, benzoxazine, maleimide

\section{Introduction}

The Diels-Alder (DA) reaction, known as $(4+2)$ cycloaddition reaction between diene and dienophile, is one of the most useful reactions in organic [1] and material synthesis $[2,3]$. DA reaction belongs to the group of 'click' reactions known as almost completely versatile, efficient and selective synthesis [4]. Furthermore, DA reactions at appropriate temperature range undergo a reverse reaction called retro-DA $(\mathrm{rDA})$ reaction that regenerates starting materials. DA adduct is the mixture of two diastereomers called endo and exo adducts. Temperature of the $\mathrm{rDA}$ reaction leading to the appearance of the endo adduct is typically lower than that of the exo adduct $[5,6]$. Due to the thermal reversibility of DA reactions, they are frequently applied in the production of remendable and recyclable materials [7-10]. During the development of self-healing material much attention is often given to the understanding the mechanistic perspective of a given reaction as much as possible. Such studies are frequently accompanied by kinetic investigations of the reaction [11-16].

Benzoxazines, because of their unique characteristics, are recently gaining much attention in polymer synthesis and design. Inclusion of DA-reaction in benzoxazine main chain is one way of integrating them with remendability. According to the literature, some work has been done in synthetic aspect of modifying benzoxazines with furan or maleimide chains. So far, the majority of the research was

\footnotetext{
${ }^{*}$ Corresponding author, e-mail: matjaz.krajnc@ffkkt.uni-1j.si (C) BME-PT
} 
focused on the modified benzoxazines describing effects of maleimide or furan functionality on the mechanical properties of polymeric benzoxazines, while the use of Diels-Alder reaction in self-healing perspective has not yet been recognized [17-22]. Needless to say, numerous studies were performed to date dealing with the DA reaction based on maleimide and furan functionalities [6, 16, 23-28]. Only a few examples in literature exist, where benzoxazines were used in DA reactions to form linear polymeric materials $[29,30]$. Authors have shown a synthetic preparation of linear benzoxazine chains, where the linker was DA based reaction, between modified benzoxazine (by furan functionality) and bismaleimides. However, their goals were to describe newly formed properties of cured benzoxazine samples, and no work was done on either describing possible remendability properties or the kinetics of the DA reaction.

On the other hand there might be a reason, why there is not yet a known self-remendable benzoxazine polymer material with DA reaction based remendability. The reason being high curing temperature needed for polymerization of benzoxazines [31, 32], usually quite above the temperature of $\mathrm{rDA}$ reaction $\left(\sim 100^{\circ} \mathrm{C}\right)$ of normally used diene and dienophile system (furan and maleimide) $[5,6]$. This means that DA connections are broken and starting compounds are formed. When this happens, maleimide double bond is exposed and starts to polymerize, which is not the desirable reaction in order to achieve self-healing based on DA reaction. This being said the curing temperatures of benzoxazines are probably the major drawbacks in the development of functional self-remendable polybenzoxazines based on DA reaction.

The focus of this paper is on the thermal evaluation of the DA reaction between $N$-phenylmaleimide (PMI) and guaiacol furfuryl amine based benzoxazine (GF). Experiments were performed in the molten state and in solution and the differences between both systems were investigated. Progress of the reaction in the absence of solvent was systematically determined by DSC analysis accompanied with ${ }^{1} \mathrm{H}$ NMR and kinetic study of the DA reaction was performed in solution. By temperature controlled FTIR (Fourier transform infrared spectroscopy) analysis kinetic parameters were derived. Higher conversions and easier manipulation of exo/ endo ratio were achieved in a molten state due to the more explicit boundary between $\mathrm{DA}$ and $\mathrm{rDA}$ reaction than in a solution. It is interesting to further investigate the use of benzoxazine based compounds bearing furan and maleimide functional groups in self-healing polymer networks activated by DielsAlder reaction. The main goal of this publication is to establish the valuable knowledge of thermal behaviour of $\mathrm{DA} / \mathrm{rDA}$ reaction in order to successfully apply self-healing in benzoxazine polymer networks.

\section{Materials and methods \\ 2.1. Materials}

Reactant $N$-phenylmaleimide (PMI, 97\%) was purchased from Aldrich (Chemie $\mathrm{GmbH}$, Steinheim, Germany). Reactant 3-(furan-2-ylmethyl)-8-methoxy3,4-dihydro- $2 H$-benzo[e][1,3] oxazine (GF) was synthesized according to the literature [33]. Aniline (99.5\%), acetic anhydride (98.5\%) and hexane were purchased from Merck (Darmstadt, Germany). Guaiacol (98\%), furfurylamine (99\%), maleic anhydride (97\%) and paraformaldehyde were purchased from Aldrich (Chemie GmbH, Steinheim, Germany), and deuterated chloroform $(99.8 \%$ D) was purchased from Euriso-top (Saint-Aubin, France). All chemicals were used as received.

\subsection{Characterization}

The proceeding of the $\mathrm{DA} / \mathrm{rDA}$ reaction was studied by differential scanning calorimetry (DSC), ${ }^{1} \mathrm{H}$ NMR (nuclear magnetic resonance) and IR spectrometry. Calorimetric studies were carried out on Mettler Toledo DSC1 instrument with intra-cooler using STAR software (Greifensee, Switzerland). In and Zn standards were used for the temperature calibration and for the determination of the instrument time constant. Samples of around $10 \mathrm{mg}$ were weighed in standard $40 \mu \mathrm{L}$ aluminium pans. DSC measurements were performed in nitrogen atmosphere with $30 \mathrm{~mL} / \mathrm{min}$ nitrogen flow rate. In order to observe the heating behaviour of each reactive compound and their mixture, DSC experiments were performed by a heating rate $10 \mathrm{~K} \cdot \mathrm{min}^{-1}$ in the range of 20 to $350^{\circ} \mathrm{C}$. For samples isothermally heated at $70^{\circ} \mathrm{C}$ DSC scans were performed from 20 to $160^{\circ} \mathrm{C}$ with the heating rate $5 \mathrm{~K} \cdot \mathrm{min}^{-1}$.

${ }^{1} \mathrm{H}$ NMR analyses were performed on a Bruker Avance III $500 \mathrm{MHz}$ NMR spectrometer (Billerica, USA) at the temperature $296 \mathrm{~K}$ and frequency $500.13 \mathrm{MHz}$ and on Bruker DPX $300 \mathrm{MHz}$ NMR at 
the temperature $296 \mathrm{~K}$ and frequency $300.13 \mathrm{MHz}$ (Billerica, USA). Deuterated chloroform $\left(\mathrm{CDCl}_{3}\right)$ was used as solvent. Endo and exo standards were obtained from DA reaction between PMI and GF by separating reaction mixture by chromatography on a silica gel column using petroleum ether:ethyl acetate (2:1) as mobile phase. Characteristic peaks monitored in reaction mixture (Figure 1): for starting materials a signal at $6.85 \mathrm{ppm}$, corresponding to maleimide protons at a carbon double bond $(\mathrm{CH}=\mathrm{CH}$, peak 3$)$, for benzoxazine singlets at 4.02 and $3.95 \mathrm{ppm}$ which correspond to $\mathrm{CH}_{2}$ in benzoxazine ring $\left(\mathrm{NCH}_{2} \mathrm{C}\right.$, peak 1) and $\mathrm{CH}_{2}$ attached to a furan ring $\left(\mathrm{NCH}_{2} \mathrm{CO}\right.$, peak 2). Products were monitored by multiplet at $5.40 \mathrm{ppm}$, corresponding to protons in a newly formed six-membered ring in both endo and exo adducts ( $\mathrm{CHCHO}$, peak 4). While doublet at $3.54 \mathrm{ppm}$ is characteristic for $\mathrm{NCH}_{2} \mathrm{CO}$ (peak 5) in endo adduct, doublets at 3.13 and $2.97 \mathrm{ppm}$ corresponds to succinimide type protons in exo-adduct $(\mathrm{COCHC}$ and $\mathrm{COCHCH}$, peak 7 and 6).

Detailed spectra are assigned as follows:

$\mathrm{N}$-phenylmaleimide (PMI): ${ }^{1} \mathrm{H} \mathrm{NMR} \quad\left(\mathrm{CDCl}_{3}\right.$, $300 \mathrm{MHz}, \delta, \mathrm{ppm}): 7.46$ (m, 2H, Ph), 7.35 (m, 3H, $\mathrm{Ph}), 6.83$ (s, 2H, $\mathrm{CH}=\mathrm{CH}$ ).

3-(furan-2-ylmethyl)-8-methoxy-3,4-dihydro-2Hbenzo[e][1,3]oxazine (GF). ${ }^{1} \mathrm{H}$ NMR $\left(\mathrm{CDCl}_{3}\right.$, $300 \mathrm{MHz}, \delta, \mathrm{ppm}): 7.41\left(\mathrm{dd}, J_{1}=0.84 \mathrm{~Hz}, J_{2}=\right.$ $1.8 \mathrm{~Hz}, 1 \mathrm{H}, \mathrm{Ar}), 6.80$ (m, 2H, Ar), 6.58 (m, 1H, Ar), $6.33\left(\mathrm{dd}, J_{1}=1.9 \mathrm{~Hz}, J_{2}=3.2 \mathrm{~Hz}, 1 \mathrm{H}, \mathrm{Ar}\right), 6.25$

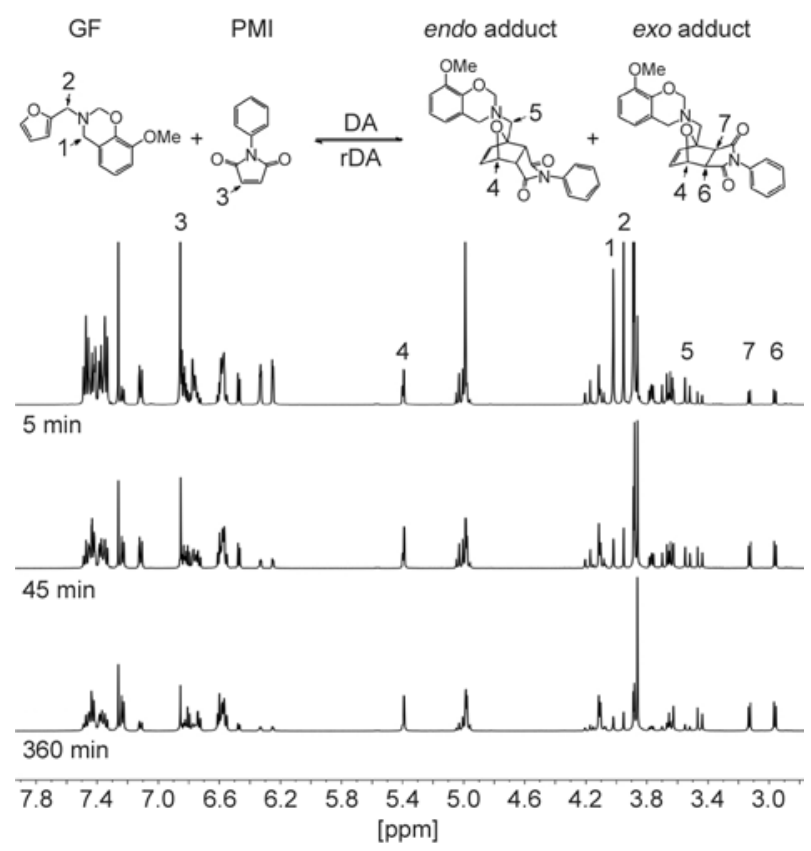

Figure 1. ${ }^{1} \mathrm{H}$ NMR assigned spectra of the reaction mixture between PMI and GF at different reaction times $\left(\mathrm{dd}, J_{1}=0.6 \mathrm{~Hz}, J_{2}=3.2 \mathrm{~Hz}, 1 \mathrm{H}, \mathrm{Ar}\right), 4.99(\mathrm{~s}, 2 \mathrm{H}$, $\left.\mathrm{OCH}_{2} \mathrm{~N}\right), 4.02\left(\mathrm{~s}, 2 \mathrm{H}, \mathrm{NCH}_{2} \mathrm{C}\right), 3.95(\mathrm{~s}, 2 \mathrm{H}$, $\left.\mathrm{NCH}_{2} \mathrm{CO}\right), 3.89$ (s, $\left.3 \mathrm{H}, \mathrm{OCH}_{3}\right)$.

(3aR,4R,7S,7aS)-4-((8-methoxy-2H-benzo[e][1,3] oxazin-3(4H)-yl)methyl)-2-phenyl-3a,4,7,7a-tetrahydro-1H-4,7-epoxyisoindole-1,3(2H)-dione (endo adduct). ${ }^{1} \mathrm{H}$ NMR $\left(\mathrm{CDCl}_{3}, 500 \mathrm{MHz}, \delta, \mathrm{ppm}\right): 7.41$ (m, 3H, Ar), 7.12 (m, 2H, Ar), 6.84 (m, 1H, Ar), 6.76 (m, 1H, Ar), $6.58(\mathrm{~m}, 2 \mathrm{H}, \mathrm{Ar}$ and $\mathrm{CH}=\mathrm{CH}), 6.47(\mathrm{~d}$, $J=5.8 \mathrm{~Hz}, 1 \mathrm{H}, \mathrm{CH}=\mathrm{CH}), 5.40\left(\mathrm{dd}, J_{1}=1.5 \mathrm{~Hz}, J_{2}=\right.$ $5.5 \mathrm{~Hz}, 1 \mathrm{H}, \mathrm{CHCHO}), 5.04(\mathrm{~d}, J=9.9 \mathrm{~Hz}, 1 \mathrm{H}$, $\left.\mathrm{OCH}_{2} \mathrm{~N}\right), 5.00\left(\mathrm{~d}, J=9.9 \mathrm{~Hz}, 1 \mathrm{H}, \mathrm{OCH}_{2} \mathrm{~N}\right), 4.19(\mathrm{~d}$, $\left.J=16.8 \mathrm{~Hz}, 1 \mathrm{H}, \mathrm{NCH}_{2} \mathrm{C}\right), 4.10(\mathrm{~d}, J=16.8 \mathrm{~Hz}, 1 \mathrm{H}$, $\left.\mathrm{NCH}_{2} \mathrm{C}\right), 3.88\left(\mathrm{~s}, 3 \mathrm{H}, \mathrm{OCH}_{3}\right), 3.78\left(\mathrm{dd}, J_{1}=5.5 \mathrm{~Hz}\right.$, $\left.J_{2}=7.7 \mathrm{~Hz}, 1 \mathrm{H}, \mathrm{COCHCH}\right), 3.69(\mathrm{~d}, J=15.1 \mathrm{~Hz}$, $\left.1 \mathrm{H}, \mathrm{NCH}_{2} \mathrm{CO}\right), 3.64$ (d, $J=7.7 \mathrm{~Hz}, 1 \mathrm{H}, \mathrm{COCHC}$ ), $3.54\left(\mathrm{~d}, J=15.1 \mathrm{~Hz}, 1 \mathrm{H}, \mathrm{NCH}_{2} \mathrm{CO}\right)$.

$(4 R, 7 S, 7 \mathrm{a} R)-4-((8-m e t h o x y-2 H$-benzo[e][1,3]oxazin3(4H)-yl)methyl)-2-phenyl-3a,4,7,7a-tetrahydro-1H4,7-epoxyisoindole-1,3(2H)-dione (exo-adduct). ${ }^{1} \mathrm{H}$ NMR $\left(\mathrm{CDCl}_{3}, 500 \mathrm{MHz}, \delta, \mathrm{ppm}\right): 7.40(\mathrm{~m}, 3 \mathrm{H}$, Ar), 7.24 (m, 2H, Ar), 6.81 (m, 1H, Ar), $6.73(\mathrm{~m}, 1 \mathrm{H}$, Ar), $6.58(\mathrm{~m}, 3 \mathrm{H}, \mathrm{Ar}$ and $\mathrm{CH}=\mathrm{CH}), 5.39(\mathrm{~d}, J=$ $1.45 \mathrm{~Hz}, 1 \mathrm{H}, \mathrm{CHCHO}), 4.98\left(\mathrm{~m}, 2 \mathrm{H}, \mathrm{OCH}_{2} \mathrm{~N}\right), 4.12$ $\left(\mathrm{m}, 2 \mathrm{H}, \mathrm{NCH}_{2} \mathrm{C}\right), 3.86\left(\mathrm{~s}, 3 \mathrm{H}, \mathrm{OCH}_{3}\right), 3.64(\mathrm{~d}, J=$ $\left.15.2 \mathrm{~Hz}, 1 \mathrm{H} \mathrm{NCH} \mathrm{H}_{2} \mathrm{CO}\right), 3.45(\mathrm{~d}, J=15.2 \mathrm{~Hz}, 1 \mathrm{H}$, $\mathrm{NCH}_{2} \mathrm{CO}$ ), 3.13 (d, $\left.J=6.5 \mathrm{~Hz} 1 \mathrm{H}, \mathrm{COCHC}\right), 2.97$ (d, $J=6.5 \mathrm{~Hz}, 1 \mathrm{H}, \mathrm{COC} \mathrm{CH}$ ).

IR spectra were recorded on Mettler Toledo ReactIR diamond composite probe (Greifensee, Switzerland) allowing in situ FTIR spectroscopy. The spectra were recorded in the range of $4000-400 \mathrm{~cm}^{-1}$. Each DA reaction was monitored via IR until equilibrium was achieved allowing kinetic parameter determination. A given reaction mixture was considered to have reached the equilibrium when the conversion remained constant over multiple reaction time points.

\subsection{Procedure of Diels-Alder experiments}

DA reaction was investigated by non-isothermal and isothermal heating of the PMI/GF mixture in the absence of solvent. Separately, the proceeding of the DA reaction was studied also in solution as a function of temperature in order to perform kinetic studies.

Diels-Alder/retro-Diels-Alder investigations were performed by isothermal heating of the PMI/GF mixture at a temperature higher than the melting point. Reactants were grounded in a mortar and mixed in stoichiometric amounts. The process of the reaction as a function of time was monitored by ${ }^{1} \mathrm{H}$ NMR 
analysis after the sample was rapidly cooled down by liquid nitrogen to the ambient temperature. Different temperatures were applied with the intention to study the conversion and exo/endo ratio.

Reactions in solution were performed in chloroform and acetonitrile at different temperatures. Stoichiometric amounts of reactants were added reaching the initial reactants' concentration $0.5 \mathrm{~mol} \cdot \mathrm{L}^{-1}$. Reactions were monitored by in situ FTIR spectroscopy. The reaction mixture was mixed with magnetic stirrer in a glass vial. Glass vial was closed with a polyethylene cap, which had a perfectly cut hole for ReactIR probe to tightly fit. Parafilm was used to additionally prevent solvent evaporation.

\section{Results and discussion}

\subsection{Diels-Alder reaction in molten state}

The product of the Diels-Alder reaction (DA adduct) is the mixture of two diastereomers called endo and exo adducts (Figure 2). While the endo compound is kinetically favoured, the exo is thermodynamically favoured and thus more stable $[5,6]$. The aim of the detailed study of the thermal behaviour of the PMI/ GF mixture is its possible further application as a self-healing polymer network.

Thermal behaviour of the reaction between PMI and GF started with DSC experiments in order to determine the approximate starting temperature of DA and retro-DA reaction. Due to the fact that both reactants melted at the same temperature, the mixture melted at lower temperature as a consequence of the freezing point depression (Figure 3). Namely, the presence of impurity in the pure compound causes a decrease in the melting point and a broadening of the melting point range. The Diels-Alder reaction started after the beginning of the melting of PMI/GF mixture (Figure 3 ) due to the higher mobility of functional groups. It can be concluded that DA reaction was actually triggered by melting of the prepared mixture. The melting peak value of the PMI/GF system was in fact lower than the sum of each individ-

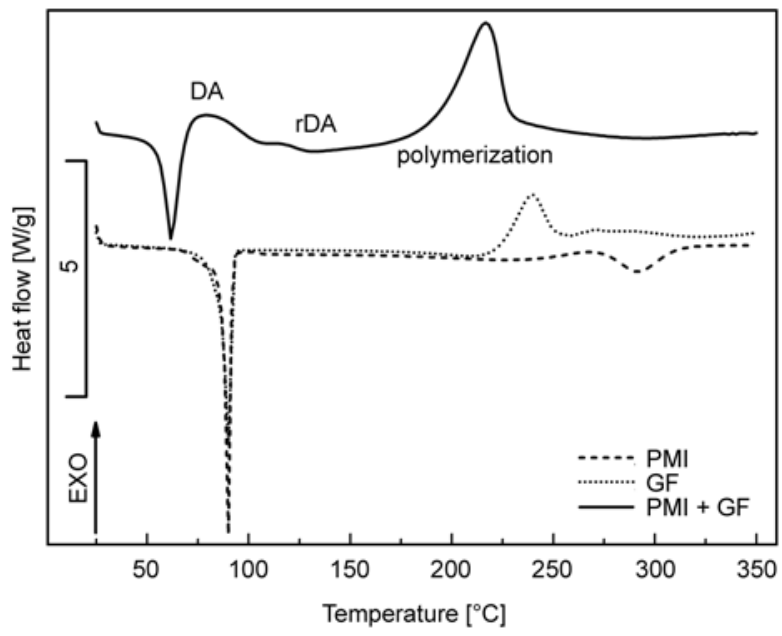

Figure 3. DSC analyses of PMI, GF and PMI/GF mixture

ual compound, which is the result of the beginning of the DA reaction and its exothermic contribution. The exothermic peak of a DA reaction reached the maxima at $80^{\circ} \mathrm{C}$ and lasted up to approximately $100^{\circ} \mathrm{C}$ when the evident endothermic peak of rDA appeared. The exothermic event from $170-240^{\circ} \mathrm{C}$ could be explained by polymerization reaction of benzoxazine and maleimide [34]. Unfortunately, there was no clear boundary between the end of the rDA reaction and start of polymerization. The exothermic peak of GF that extended over $200^{\circ} \mathrm{C}$ represents a polymerization reaction of benzoxazine [33]. On the other hand, we presumed that DSC curve of PMI showed an endothermic peak at around $275^{\circ} \mathrm{C}$, due to the combination of polymerization reaction of maleimide and its evaporation at higher temperatures.

It is worth mentioning that DSC analysis is not an appropriate tool for kinetic studies of DA reaction, because accurate differentiation between the indiviual processes is not clear. For that reason non-isothermal heating was associated with ${ }^{1} \mathrm{H}$ NMR analysis allowing detailed insight into the reaction process as a function of temperature (Figure 4). After reaching the examined temperature by a heating rate of $10 \mathrm{~K} \cdot \mathrm{min}^{-1}$, the sample was rapidly cooled down by

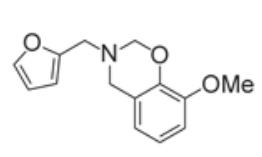

GF

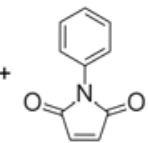

PMI
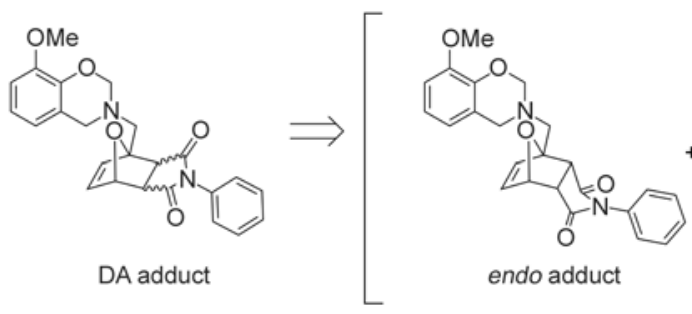

endo adduct

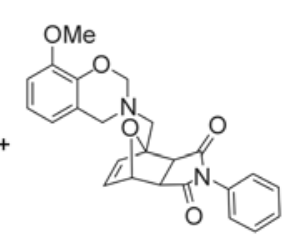

exo adduct

Figure 2. Diels-Alder reaction between benzoxazine bearing furan group (GF) and $N$-phenylmaleimide (PMI) forms DAadduct 


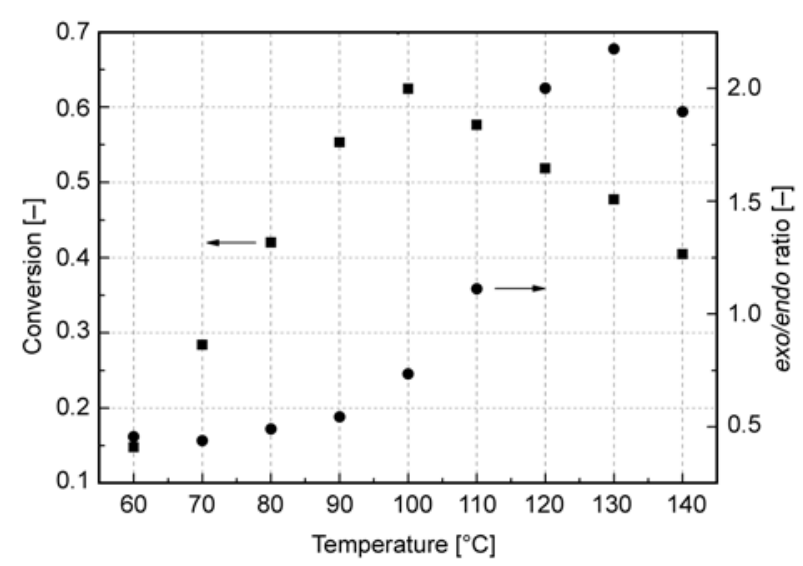

Figure 4. Conversion and exo/endo ratio for non-isothermal heating of a PMI/GF mixture in a range from 60 to $140^{\circ} \mathrm{C}$

liquid nitrogen. The range from 60 to $140{ }^{\circ} \mathrm{C}$ was studied analysing the conversion and endo/exo adducts behaviour. The conversion linearly increased up to $100^{\circ} \mathrm{C}$, when a linear drop in conversion value was observed as a consequence of $\mathrm{rDA}$ reaction. The mentioned followed also from the heat flow of a DSC analysis, where a shift from exothermic to insignificant endothermic peak was observed.

In contrast to the measured value, more evident endothermic behaviour was expected due to the progress of endothermic rDA reaction and drop in conversion from 0.62 to 0.40 . Interestingly, although the conversion started to decrease, the increase of exo/endo ratio was observed up to $130^{\circ} \mathrm{C}$ due to the thermodynamically favoured exo adduct. Additionally, when the sample was kept at $140^{\circ} \mathrm{C}$ for another 10 minutes, no further drop in the conversion was observed. This may indicate that formed adduct was transformed into reactants by $\mathrm{rDA}$ reaction instantaneously. By achieving merely $15 \%$ of conversion at $60^{\circ} \mathrm{C}$ it was proven that $\mathrm{DA}$ reaction started during the melting of the sample.

Further investigation was designed towards the isothermal heating of PMI/GF mixture above the temperature of the melting point. The intention was to observe the evolution of conversion and exo/endo ratio as a function of time. Although the self-healing effects are out of scope of this research, renewing the exo/endo ratio in self-healing studies could be interesting. The precise results of endo and exo compounds were likewise obtained by ${ }^{1} \mathrm{H}$ NMR analysis. Since only DA reaction during isothermal heating was studied thoroughly, only the results applying temperatures up to $100^{\circ} \mathrm{C}$ were obtained.
The temperature of $100^{\circ} \mathrm{C}$ was used as a limited temperature between DA and $\mathrm{rDA}$ reaction.

Considering the results of DSC analysis the first experiment was performed at $60^{\circ} \mathrm{C}$. The sample fully melted after approximately 15 minutes, when the sample was first analysed, and reached the final conversion at $75 \%$. Clearly, the reaction at higher temperature was faster; however the same final conversion was achieved at 70 and $80^{\circ} \mathrm{C}$ and reached the final value after 50 minutes. Differently, at 90 and $100^{\circ} \mathrm{C}$ conversion after 180 minutes started to decrease due to the effect of the beginning of rDA reaction. Although the conversion at 70 and $80^{\circ} \mathrm{C}$ was similar, there was an important difference between the ratio of exo/endo adduct. Due to the fact that exo adduct is thermodynamically favoured [5, 6], the ratio is increasing with temperature and time. At $60^{\circ} \mathrm{C}$ endo adduct was the predominant product and there was no significant increase in ratio by time indicating that temperature was not yet in favour of exo emergence. Obviously, at prolonged heating times, temperatures of about $90^{\circ} \mathrm{C}$ indicated the end of DA and start of $\mathrm{rDA}$ reaction. This trend was evident also from the exolendo ratio. While up to 60 minutes the increase of the ratio was linear and higher than at lower temperatures, afterwards the ratio started to decrease gradually. The effect of the heating temperature on exo/endo ratio is even more evident at $100^{\circ} \mathrm{C}$, when the ratio started to decrease after 30 minutes. Among that, the decrease in conversion was observed after 60 minutes. The trend shown in Figure 5 therefore suggests that the extension of the heating time does not lead to further progression of the reaction; it does, however, affect the exo and endo ratio. The maximum amount of exo adduct could consequently be achieved in the range of $70-80^{\circ} \mathrm{C}$ at extended heating times. Conversely, if the goal is to maximize of endo adduct, the temperature should be as low as possible and the heating should be stopped right after the equilibrium conversion is achieved.

It has been previously reported [5] that rDA reaction of endo adduct has significantly lower activation barrier compared to exo adduct. Calorimetric analyses should noticeably demonstrate the progress of the endo and exo adduct in $\mathrm{rDA}$ reaction. For that reason DA adduct obtained in isothermal heating at $70^{\circ} \mathrm{C}$ was further analysed by DSC analysis (Figure 6). When sample was isothermally heated for 1 

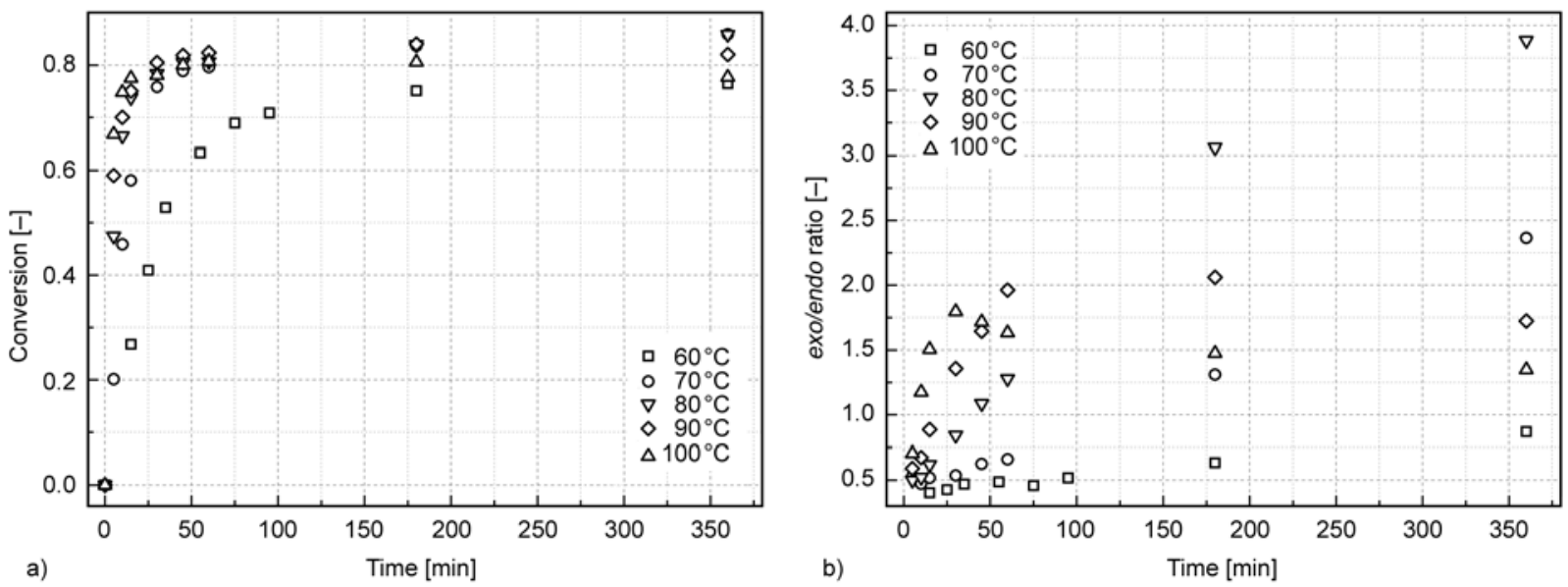

Figure 5. Progress of conversion (a) and exo/endo (b) for isothermal experiments at different temperatures in a molten state

and 3 hours (initial exo/endo ratio was 0.66 and 1.31 , respectively) an exothermic peak occurred inside the broad endothermic peak. On the other hand, at higher exo/endo ratios (2.36 for 6 hours and 3.83 for 12 hours) the previously observed exothermic peak disappeared.

The appearance of the exothermic peak at 1 and 3 hours could be explained by a three-step process. First the endothermic peak appeared as a result of transformation of endo DA adduct into PMI and GF driven by rDA reaction. Following that, the new exo/endo adducts mixture was quickly formed leading to the exothermic peak on DSC thermogram. In conclusion, endothermic peak that started at approximately $105^{\circ} \mathrm{C}$ belonged to the exo's rDA reaction (Figure 6). By increasing the sample's heating time, the previously observed exothermic peak of exo adduct disappeared due to the increasing exo/endo ratio (Figure $5 \mathrm{~b}$ ). It can be deduced that the amount of endo adduct in the exo/endo mixture at 6 and

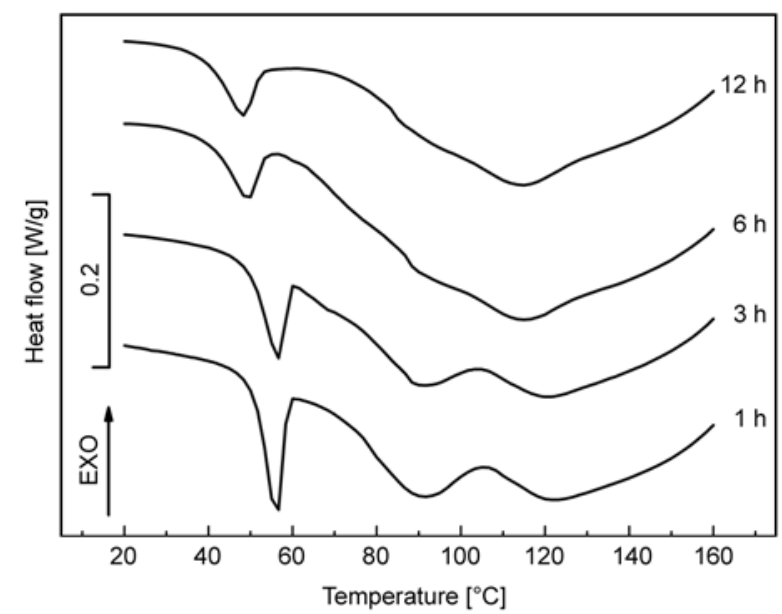

Figure 6. Evolution of DSC thermograms versus time of pre-cured samples of $\mathrm{PMI} / \mathrm{GF}$ at $70^{\circ} \mathrm{C}$
12 hours is apparently too low to have any exothermic effect noticeable by DSC method. DSC scans at 6 and 12 hours are consequently showing only broad endothermic peak corresponding mainly to the retroDA reaction of exo adduct (Figure 6).

The general idea of further use of DA reaction is in self-healing applications of polymer networks. As it has already been mentioned, the $\mathrm{rDA}$ reaction of endo adduct is faster than the $\mathrm{rDA}$ reaction of its stereoisomer, exo adduct. Hence, in the synthesis of material depending only on DA linkages, two principles could be used. The first could be based on the synthesis of material at low DA reaction temperature $\left(60-70^{\circ} \mathrm{C}\right.$ for our system) favouring the majority of endo DA connections. The damaged material can be healed also at lower temperature; at a temperature high enough to convert endo form into exo, however not high enough to reach the rDA reaction of exo adduct. Under the outlined condition the material could be conditionally healed by a pulse heating in the endo rDA reaction range without deformation of the material shape. In this case, the exo adduct would actually play a role of a structural basis of the material.

It is worth mentioning that such principle of a selfhealing is limited. Once all the endo adduct is transformed into exo form, only the step of exo $\mathrm{rDA}$ reaction remains. The second principle depends on selfhealing of the material at elevated temperatures by triggering the rDA reaction of the exo adduct meaning the recycling of material to the initial reactants. Consequently, if the material is based only on DielsAlder bonds, breakdown of the exo adduct leads to the material shape loss. Nevertheless, the main issue of benzoxazine polymerization below the temperature of the $\mathrm{rDA}$ reaction remains, however, future 
study based on preliminary DA/rDA study would be interesting.

\subsection{Kinetic study of the Diels-Alder reaction in acetonitrile and chloroform}

The kinetics of the model DA reaction in a solvent was monitored by IR spectroscopy. Chloroform and acetonitrile were used as solvents due to the optimal visibility of reactants' peaks shifting as a function of time. To study the DA model reaction kinetics, DA reactions between PMI and GF were carried out at different temperatures $\left(30,40\right.$ and $50^{\circ} \mathrm{C}$ for chloroform, and $40,50,60$ and $70^{\circ} \mathrm{C}$ for acetonitrile) until the equilibrium was reached. DA reaction in a solution started at a lower temperature than in the molten state due to the solvent-diene-dienophile interaction, when in molten state the mobility of the functional group was achieved via sample melting. Figure 7 shows the evolution of IR spectra versus time of the reaction between PMI and GF in acetonitrile and chloroform presenting the characteristic peaks and their increase or depletion.

According to the results of the preliminary experiments we focused on the signal with the wavenumber $832 \mathrm{~cm}^{-1}$, since the peak was isolated and unaffected by solvent or other reactant. The observed peak showed the decrease in intensity and belonged to the characteristic $\mathrm{C}-\mathrm{H}$ vibration of double bond in PMI. Due to the overlapping of the reactant with either solvent and/or the opposite reactant, other peaks were inappropriate for quantitative measurements and further conversion calculations. To clarify, since the stoichiometric amount of reactants was presented in the mixture, furan and maleimide functionalities are consumed at the same rate. Consequently, it is enough to observe either maleimide or furan functional group. The formation of the DAadduct may be slightly detected at $1778 \mathrm{~cm}^{-1}$, however the occurrence was barely visible. Another specific absorption of DA adducts was detected at $1181 \mathrm{~cm}^{-1}$, even though it was observable only in acetonitrile. The signal at $1151 \mathrm{~cm}^{-1}$ in acetonitrile (shifted to $1148 \mathrm{~cm}^{-1}$ in chloroform) belonged to the $\mathrm{C}-\mathrm{N}-\mathrm{C}$ vibration. Peak at $1600 \mathrm{~cm}^{-1}$ belonged to the $\mathrm{C}=\mathrm{C}$ vibration in $\mathrm{PMI}$ and $\mathrm{GF}$, whereas $1515 \mathrm{~cm}^{-1}$ represented $\mathrm{C}-\mathrm{H}$ vibration in aromatic ring. Unfortunately, distinguishing between the endo and exo form is not possible by IR analysis, which is why the formation of summarized DA adduct form was merely predicted.

Due to the fact that the ReactIR allows in situ measurements its usage is ideal for DA reaction kinetic studies. However, in DA kinetic studies IR spectroscopy is often mentioned as inaccurate and used preferably only for qualitative measurements. For that reason, the accuracy of the maleimide group consumption and conversion calculations were verified performing two concurrent reactions at $40^{\circ} \mathrm{C}$ : one performed in chloroform and analysed by ReactIR, and other performed in deuterated chloroform followed by ${ }^{1} \mathrm{H}$ NMR characterization. The comparison of the results showed that the calculations of conversion from the IR absorbance of the characteristic peak showed similar results as the conversion from ${ }^{1} \mathrm{H}$ NMR peak integrals (Figure 8). Reasonably, due to the simplicity of the reaction implementation at different temperatures, all reactions were analysed by the ReactIR instrument further on. It
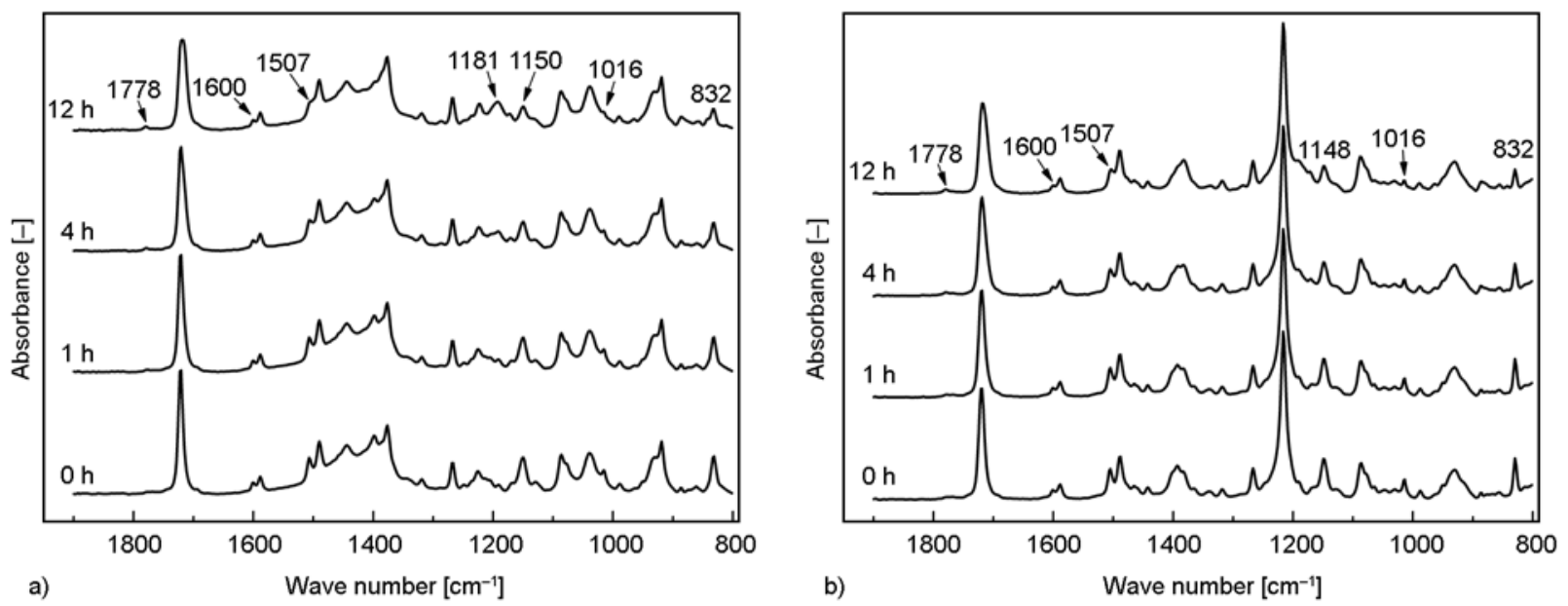

Figure 7. Evolution of the ReactIR spectra of the DA reaction between PMI and GF in acetonitrile (a) and chloroform (b) at $40^{\circ} \mathrm{C}$ 


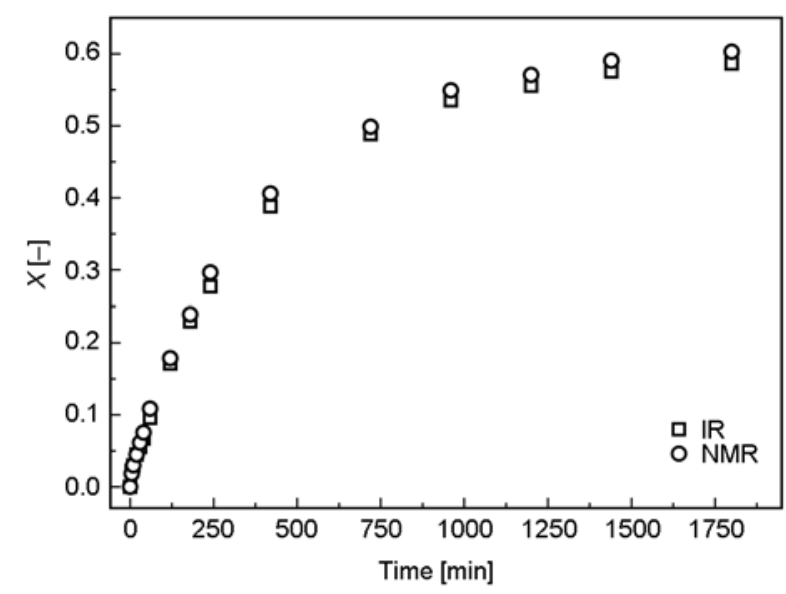

Figure 8. Experimental results of reaction performed in chloroform analysed separately by IR and ${ }^{1} \mathrm{H}$ NMR method

has to be noted that calibration curves of peak intensities at different concentrations of reactants showed good linear relationship in both chloroform and acetonitrile, which is why only the absorbance values were used in conversion calculations.

The concentration of PMI being proportional to the absorbance at $832 \mathrm{~cm}^{-1}$, conversion $X$ is expressed by Equation (1):

$X(t)=1-\frac{A_{\mathrm{PMI}}(t)}{A_{\mathrm{PMI}}(0)}$

To determine the kinetic parameters, the overall reaction rate of maleimide $(\mathrm{M})$ in the reversible DA reaction with furan (F) is written by Equation (2):

$\frac{\mathrm{d}[\mathrm{M}]}{\mathrm{d} t}=-k_{\mathrm{DA}}[\mathrm{M}][\mathrm{F}]+k_{\mathrm{rDA}}[\mathrm{A}]$

where $[\mathrm{M}]$ is the concentration of maleimide as PMI functional group, $[\mathrm{F}]$ is the concentration of

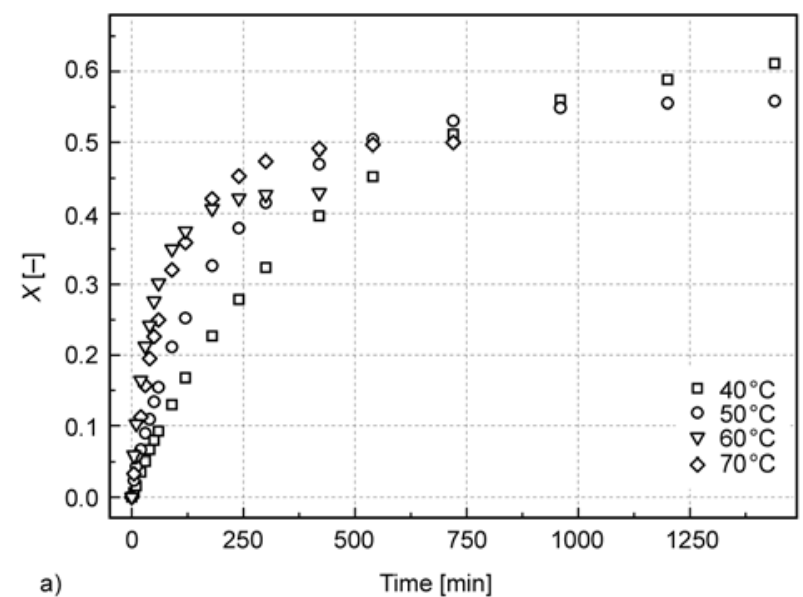

furan as GF function group, and [A] is the concentration of adduct. For the purposes of kinetic studies DA adduct was the sum of its endo and exo form. Kinetic parameters $k_{\mathrm{DA}}$ and $k_{\mathrm{rDA}}$ presents the reaction rate constants of the forward and reverse DA reaction. For stoichiometric mixtures of PMI and GF, Equation (2) can be re-written in a form of conversion $X$ (Equation (3)):

$\frac{\mathrm{d} X}{\mathrm{~d} t}=k_{\mathrm{DA}}[\mathrm{M}]_{0}(1-X)^{2}-k_{\mathrm{rDA}} X$

Once the equilibrium conversion is known, the equilibrium constant can be calculated as (Equation (4)):

$K_{\mathrm{C}}=\frac{k_{\mathrm{DA}}}{k_{\mathrm{rDA}}}=\frac{[\mathrm{A}]}{[\mathrm{M}][\mathrm{F}]}=\frac{X}{[\mathrm{M}]_{0}\left(1-X_{\mathrm{e}}\right)^{2}}$

where $[\mathrm{M}]_{0}$ is the initial PMI concentration. Further on, when applying equilibrium conversion and equilibrium constant in Equatoin (3), linearized form of Equatoin (3) can be derived and used in verification of bimolecular-type second-order reversible reaction (Equatoin (5)).

$\ln \left(\frac{X_{\mathrm{e}}\left(1-X_{\mathrm{e}} X\right)}{X_{\mathrm{e}}-X}\right)=k_{\mathrm{DA}}[\mathrm{M}]_{0}\left(\frac{1}{X_{\mathrm{e}}}-X_{\mathrm{e}}\right) t$

The results of experiments in acetonitrile and chloroform are straightforward. Since the derivation of experimental data and kinetic parameters followed the same procedure, graphical presentation is demonstrated only for experiments in acetonitrile (Figure 9). Figure 9 shows that the higher the temperature the faster the conversion increases, which is in accordance with the kinetic laws.

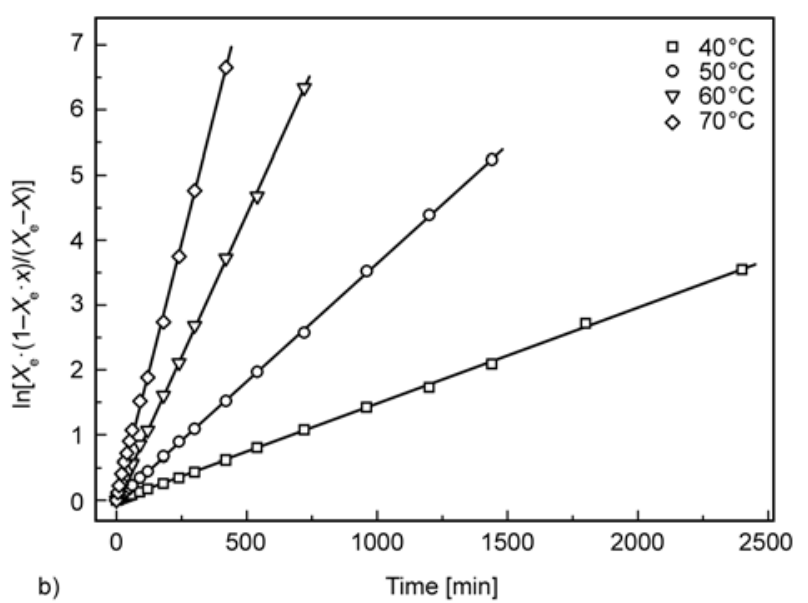

Figure 9. Evolution of the conversion versus time at different temperatures (a) and bimolecular second-order reversible reaction kinetic model (b) 
Table 1. Equilibrium conversion $\left(X_{\mathrm{e}}\right)$ and kinetic rate constants $\left(k_{\mathrm{DA}}, k_{\mathrm{rDA}}\right)$ describing the kinetics of DA reaction as indicated in Figure 9

\begin{tabular}{|c|c|c|c|c|c|c|}
\hline \multirow[b]{2}{*}{$\begin{array}{c}T \\
{\left[{ }^{\circ} \mathbf{C}\right]}\end{array}$} & \multicolumn{3}{|c|}{ Acetonitrile } & \multicolumn{3}{|c|}{ Chloroform } \\
\hline & $X_{\mathrm{e}}$ & $\begin{array}{c}k_{\mathrm{DA}} \cdot 10^{3} \\
{\left[\mathrm{~L} \cdot \mathrm{mol}^{-1} \cdot \min ^{-1}\right]}\end{array}$ & $\begin{array}{c}k_{\mathrm{rDA}} \cdot 10^{3} \\
{\left[\mathrm{~min}^{-1}\right]}\end{array}$ & $X_{\mathrm{e}}$ & $\begin{array}{c}k_{\mathrm{DA}} \cdot 10^{3} \\
{\left[\mathrm{~L} \cdot \mathrm{mol}^{-1} \cdot \min ^{-1}\right]}\end{array}$ & $\begin{array}{c}k_{\mathrm{rDA}} \cdot 10^{3} \\
{\left[\min ^{-1}\right]}\end{array}$ \\
\hline 30 & & & & 0.70 & 1.902 & 0.122 \\
\hline 40 & 0.66 & 3.461 & 0.303 & 0.60 & 3.525 & 0.470 \\
\hline 50 & 0.56 & 5.939 & 1.027 & 0.52 & 6.819 & 1.511 \\
\hline 60 & 0.50 & 11.917 & 2.979 & & & \\
\hline 70 & 0.43 & 16.704 & 6.311 & & & \\
\hline
\end{tabular}

Our studied system fitted typical bimolecular second-order reversible reaction (Figure 9b). Applying the Equation (5), a satisfactory fit was achieved from which kinetic parameters $k_{\mathrm{DA}}$ and $k_{\mathrm{rDA}}$ were calculated (Table 1). The goodness of fit was verified by $R^{2}$ value, which was over 0.999 for all experiments. The DA reaction was in balance between the blocked and the unblocked form. The ratio depended upon the temperature and reached the plateau during the rDA reaction (Figure 9). By increasing the reaction temperature the equilibrium conversion started to decrease as a consequence of rDA effect. In order to determine the $\mathrm{DA} / \mathrm{rDA}$ equilibrium as a function of temperature the reaction system was allowed to reach the equilibrium. It took more than two days to reach the equilibrium at 30 and $40^{\circ} \mathrm{C}$. The kinetic parameters in chloroform were slightly higher than in acetonitrile, which affected also the equilibrium conversion that was consequently higher in acetonitrile than in chloroform.

The reaction between PMI and GF was carried out at different temperatures. For that reason it is possible to apply the Arrhenius law (Equation (6)) with the aim to determine activation energy and preexponential factor:

$\ln k=-\frac{E_{\mathrm{a}}}{R T}+\ln A$

The activation energy for DA in acetonitril was 48.4 and $51.9 \mathrm{~kJ} \cdot \mathrm{mol}^{-1}$ in chloroform. For the reversible part the activation energy values were 91.0 and $102.3 \mathrm{~kJ} \cdot \mathrm{mol}^{-1}$, respectively. The determined activation energies were reasonable and expected according to the already reported values for maleimide/ furan systems [24, 27]. Nevertheless, the observed differences originated from the nature of DA building blocks and network density.

While in molten state the DA reaction started when reactants started to melt as a prerequisite for func- tional groups mobility, the DA reaction in solution was possible even at ambient temperature, however, at a very slow reaction rate. According to the literature, the solvation energy contributes to the total free energy of the reactants and the transition states. For that reason, when in molten state the conversion at $70^{\circ} \mathrm{C}$ reached $75 \%$ constituted mainly of endo adduct, in acetonitrile the equilibrium conversion of merely $45 \%$ was achieved. The reaction equilibrium in solution was obviously much more affected by the rDA reaction, which started to affect at lower temperatures rather than in molten state. Therefore, there is no clear boundary between the end of the DA reaction and the beginning of the rDA reaction in solution, which makes its use difficult in preparing the DA adduct at high conversion with desirable exo/endo ratio. For that reason synthesis of the product depends on thermo-reversibility of DA reaction which is much more suitable in the molten state, where the limit between $\mathrm{DA} / \mathrm{rDA}$ reactions is unambiguous.

\section{Conclusions}

In summary, this study showed a detailed investigation of the DA reaction and provided useful knowledge for further use in self-healing polymer networks. Experiments were performed in the molten state and in solution and the differences between both forms were discussed. By non-isothermal DSC heating of the PMI and GF mixture accompanied by ${ }^{1} \mathrm{H}$ NMR, approximate temperatures of the DA and rDA reaction were determined. We especially focused on exo/endo ratio and its dependence on temperature, and on the Diels-Alder kinetics. The activation energy and pre-exponential factor of the forward and reverse DA reaction in a solution were determined by FTIR spectroscopy. The obtained activation energies in acetonitrile and chloroform agreed to be similar with those reported in the literature. 
Moreover, the reaction equilibrium in solution is significantly affected by rDA reaction in comparison to the molten state. Considering the reaction in the molten state compared to reaction in solution, there was a clear temperature difference between the length of the DA reaction and $\mathrm{rDA}$ reaction which followed afterwards. For that reason, preparation of the material based on the absence of solvent is a better option as the reaction is easily manageable from a conversion and exo/endo ratio perspective. The presented paper showed the already known common points of the Diels-Alder reaction extended to the detailed thermal behaviour of the reaction in a molten state and solution. Due to this study it is possible to adapt the obtained knowledge in further self-healing studies.

\section{Acknowledgements}

The financial support of this work by the Slovenian Research Agency (Grant P2-0191 and grant N2-0033) is gratefully acknowledged.

\section{References}

[1] Woodward R. B., Sondheimer F., Taub D., Heusler K., McLamore W. M.: The total synthesis of steroids. Journal of the American Chemical Society, 74, 4223-4251 (1952).

DOI: $10.1021 / \mathrm{ja} 01137 \mathrm{a} 001$

[2] Tasdelen M. A.: Diels-Alder 'click' reactions: Recent applications in polymer and material science. Polymer Chemistry, 2, 2133-2145 (2011).

DOI: $10.1039 / \mathrm{C} 1 \mathrm{PY} 00041 \mathrm{~A}$

[3] Liu Y-L., Chuo T-W.: Self-healing polymers based on thermally reversible Diels-Alder chemistry. Polymer Chemistry, 4, 2194-2205 (2013). DOI: $10.1039 / \mathrm{c} 2$ py20957h

[4] Kolb H. C., Finn M. G., Sharpless K. B.: Click chemistry: Diverse chemical function from a few good reactions. Angewandte Chemie International Edition, 40, 2004-2021 (2001).

DOI: 10.1002/1521-3773(20010601)40:11<2004::AIDANIE2004>3.0.CO;2-5

[5] Canadell J., Fischer H., De With G., van Benthem R.: Stereoisomeric effects in thermo-remendable polymer networks based on Diels-Alder crosslink reactions. Journal of Polymer Science Part A: Polymer Chemistry, 48, 3456-3467 (2010).

DOI: $10.1002 /$ pola.24134

[6] Froidevaux V., Borne M., Laborbe E., Auvergne R., Gandini A., Boutevin B.: Study of the Diels-Alder and retro-Diels-Alder reaction between furan derivatives and maleimide for the creation of new materials. RSC Advances, 5, 37742-37754 (2015).

DOI: $10.1039 / \mathrm{c} 5 \mathrm{ra} 01185 \mathrm{j}$
[7] Li J., Zhang G., Deng L., Zhao S., Gao Y., Jiang K., Sun R., Wong C.: In situ polymerization of mechanically reinforced, thermally healable graphene oxide/polyurethane composites based on Diels-Alder chemistry. Journal of Materials Chemistry A, 2, 20642-20649 (2014).

DOI: $10.1039 / \mathrm{C} 4 \mathrm{TA} 04941 \mathrm{~A}$

[8] Yu S., Zhang R., Wu Q., Chen T., Sun P.: Bio-inspired high-performance and recyclable cross-linked polymers. Advanced Materials, 25, 4912-4917 (2013). DOI: $10.1002 /$ adma.201301513

[9] Pramanik N. B., Nando G. B., Singha N. K.: Self-healing polymeric gel via RAFT polymerization and DielsAlder click chemistry. Polymer, 69, 349-356 (2015). DOI: $10.1016 /$ j.polymer.2015.01.023

[10] Kötteritzsch J., Hager M. D., Schubert U. S.: Tuning the self-healing behavior of one-component intrinsic polymers. Polymer, 69, 321-329 (2015). DOI: $10.1016 /$ j.polymer.2015.03.027

[11] Weizman H., Nielsen C., Weizman O. S., NematNasser S.: Synthesis of a self-healing polymer based on reversible Diels-Alder reaction: An advanced undergraduate laboratory at the interface of organic chemistry and materials science. Journal of Chemical Education, 88, 1137-1140 (2011).

DOI: $10.1021 / \mathrm{ed} 101109 \mathrm{f}$

[12] Du P., Wu M., Liu X., Zheng Z., Wang X., Joncheray T., Zhang Y.: Diels-Alder-based crosslinked self-healing polyurethane/urea from polymeric methylene diphenyl diisocyanate. Journal of Applied Polymer Science, 131, 40234/1-40234/7 (2014).

DOI: $10.1002 / a p p .40234$

[13] Li J., Zhang G., Deng L., Jiang K., Zhao S., Gao Y., Sun R., Wong C.: Thermally reversible and self-healing novolac epoxy resins based on Diels-Alder chemistry. Journal of Applied Polymer Science, 132, 42167/142167/7 (2015).

DOI: $10.1002 / a p p .42167$

[14] Tian Q., Yuan Y. C., Rong M. Z., Zhang M. Q.: A thermally remendable epoxy resin. Journal of Materials Chemistry, 19, 1289-1296 (2009).

DOI: $10.1039 / \mathrm{b} 811938 \mathrm{~d}$

[15] Mineo P., Barbera V., Romeo G., Ghezzo F., Scamporrino E., Spitaleri F., Chiacchio U.: Thermally reversible highly cross-linked polymeric materials based on furan/ maleimide Diels-Alder adducts. Journal of Applied Polymer Science, 132, 42314/1-42314/9 (2015). DOI: $10.1002 / a p p .42314$

[16] Bose R. K., Kötteritzsch J., Garcia S. J., Hager M. D., Schubert U. S., van der Zwag S.: A rheological and spectroscopic study on the kinetics of self-healing in a single-component Diels-Alder copolymer and its underlying chemical reaction. Journal of Polymer Science Part A: Polymer Chemistry, 52, 1669-1675 (2014). DOI: $10.1002 /$ pola. 27164 
[17] Agag T., Takeichi T.: Preparation, characterization, and polymerization of maleimidobenzoxazine monomers as a novel class of thermosetting resins. Journal of Polymer Science Part A: Polymer Chemistry, 44, 1424-1435 (2006). DOI: $10.1002 /$ pola.21245

[18] Ambrožič R., Šebenik U., Krajnc M.: Synthesis, curing kinetics, thermal and mechanical behavior of novel cardanol-based benzoxazines. Polymer, 76, 203-212 (2015). DOI: $10.1016 /$ j.polymer.2015.08.065

[19] Gaina C., Ursache O., Gaina V., Musteata V-E.: High performance thermosets based on multifunctional intermediates containing allyl, maleimide and benzoxazine groups. Journal of Polymer Research, 20, 263/1-263/11 (2013). DOI: 10.1007/s10965-013-0263-9

[20] Jin L., Agag T., Ishida H.: Bis(benzoxazine-maleimide)s as a novel class of high performance resin: Synthesis and properties. European Polymer Journal, 46, 354-363 (2010).

DOI: $10.1016 /$ j.eurpolymj.2009.09.013

[21] Liu Y-L., Chang C-Y., Hsu C-Y., Tseng M-C., Chou CI.: Preparation, characterization, and properties of fluorene-containing benzoxazine and its corresponding cross-linked polymer. Journal of Polymer Science Part A: Polymer Chemistry, 48, 4020-4026 (2010). DOI: $10.1002 /$ pola. 24187

[22] Zhong H., Lu Y., Chen J., Xu W., Liu X.: Preparation, characterization, and polymerization of novel maleimidobenzoxazine containing carboxylic moiety and its cocuring behaviors with epoxy resin. Journal of Applied Polymer Science, 118, 705-710 (2010). DOI: 10.1002/app.32503

[23] Liu X., Du P., Liu L., Zheng Z., Wang X., Joncheray T., Zhang Y.: Kinetic study of Diels-Alder reaction involving in maleimide-furan compounds and linear polyurethane. Polymer Bulletin, 70, 2319-2335 (2013).

DOI: 10.1007/s00289-013-0954-8

[24] Adzima B. J., Aguirre H. A., Kloxin C. J., Scott T. F., Bowman C. N.: Rheological and chemical analysis of reverse gelation in a covalently cross-linked DielsAlder polymer network. Macromolecules, 41, 91129117 (2008).

DOI: $10.1021 / \mathrm{ma} 801863 \mathrm{~d}$

[25] Goiti E., Heatley F., Huglin M. B., Rego J. M.: Kinetic aspects of the Diels-Alder reaction between poly (styrene-co-furfuryl methacrylate) and bismaleimide. European Polymer Journal, 40, 1451-1460 (2004). DOI: 10.1016/j.eurpolymj.2004.01.036
[26] Koehler K. C., Durackova A., Kloxin C. J., Bowman C. N.: Kinetic and thermodynamic measurements for the facile property prediction of Diels-Alder-conjugated material behavior. AIChE Journal, 58, 3545-3552 (2012).

DOI: $10.1002 /$ aic. 13733

[27] Scheltjens G., Diaz M. M., Brancart J., Van Assche G., Van Mele B.: A self-healing polymer network based on reversible covalent bonding. Reactive and Functional Polymers, 73, 413-420 (2013).

DOI: 10.1016/j.reactfunctpolym.2012.06.017

[28] Yuan Y. C., Yin T., Rong M. Z., Zhang M. Q.: Self healing in polymers and polymer composites. Concepts, realization and outlook: A review. Express Polymer Letters, 2, 238-250 (2008).

DOI: 10.3144 /expresspolymlett.2008.29

[29] Chen N-H., Li H-Y., Lai J-Y., Liu Y-L.: Synthesis and characterization of benzoxazine-containing, crosslinkable, and sulfonated polymer through Diels-Alder reaction for direct methanol fuel cells. Polymer, 54, 20962104 (2013). DOI: $10.1016 /$ j.polymer.2013.02.037

[30] Chou C-I., Liu Y-L.: High performance thermosets from a curable Diels-Alder polymer possessing benzoxazine groups in the main chain. Journal of Polymer Science Part A: Polymer Chemistry, 46, 6509-6517 (2008). DOI: $10.1002 /$ pola.22960

[31] Chow W. S., Grishchuk S., Burkhart T., Karger-Kocsis J.: Gelling and curing behaviors of benzoxazine/epoxy formulations containing 4,4'-thiodiphenol accelerator. Thermochimica Acta, 543, 172-177 (2012).

DOI: $10.1016 /$ j.tca.2012.05.015

[32] Ručigaj A., Alič B., Krajnc M., Šebenik U.: Curing of bisphenol A-aniline based benzoxazine using phenolic, amino and mercapto accelerators. Express Polymer Letters, 9, 647-657 (2015).

DOI: 10.3144 /expresspolymlett.2015.60

[33] Wang C., Sun J., Liu X., Sudo A., Endo T.: Synthesis and copolymerization of fully bio-based benzoxazines from guaiacol, furfurylamine and stearylamine. Green Chemistry, 14, 2799-2806 (2012). DOI: $10.1039 / \mathrm{c} 2 \mathrm{gc} 35796 \mathrm{~h}$

[34] Liu Y-L., Yu J-M.: Cocuring behaviors of benzoxazine and maleimide derivatives and the thermal properties of the cured products. Journal of Polymer Science Part A: Polymer Chemistry, 44, 1890-1899 (2006). DOI: $10.1002 /$ pola. 21290 